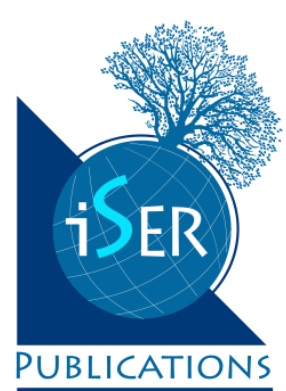

\title{
"Public-based-Learning": The Place of Publics in Exploring Environmental Controversies for Pedagogical Purposes
}

François Mélard

Université de Liège, BELGIUM

Dorothée Denayer

Université de Liège, BELGIUM

Nathalie Semal

Université de Liège, BELGIUM

•Received 11 March $2015 \bullet$ Revised 19 June $2015 \bullet$ Accepted 07 September 2015

This article examines a 15 year-old master level seminar dedicated to the exploration of local and complex environmental issues marked by scientific or technological uncertainties. Following a pragmatic learning approach, we focus our discussion on a triadic relationship between supervisors, students and various concerned publics. A local flood management controversy in Belgium will help to illustrate our approach and point to some learning outcomes. On the basis of this pedagogical experience, we propose to shift from Problem-based-learning towards Public-based-learning that rests on the comparison of the various ways a problem is defined by publics. This comparative approach allows us to deduce a plurality of modes of involvement mobilized in the management of the environmental problems.

Keywords: Public-based-Learning, pragmatic learning approach, higher education, environmental controversies, posture, symmetry

\section{INTRODUCTION}

Environmental crises confront scientists and managers with a paradox that they cannot solve but with which they must work. On the one hand, they call for the identification of effective solutions, at the risk of seeing the situation deteriorate quickly, but on the other hand, they are and continue to be rife with scientific or technical uncertainty that necessitates caution. How does one train future managers to tackle a complex environmental problem with "scientific rigour", when knowledge of the issues and the solutions for them are uncertain? When defining the problem is part of the problem itself? When tested methods, intervention protocols, established operating procedures, and so on seem to miss the mark?

"How does one learn from such a complex situation?" First of all, we wager that our students, as future environmental managers, would not be content with

Correspondence: François Mélard,

Avenue de Longwy, 185, 6700 Arlon, BELGIUM

E-mail: f.melard@ulg.ac.be

doi: 10.12973/ijese.2015.283a 
scientific "certainties" about the subject of their study. We urge them to take an exploratory approach that is aimed at both enriching their understanding of the problem and developing their reflexivity as they tackle it. We also suggest an approach that is in touch with the occupational practices in which they were trained. In the following pages, we will illustrate the ways in which we have addressed these issues in our teaching practices for fifteen years, and how we have engaged them in a collaborative controversy inquiry (Sadler et al., 2007; Savery, 2006) for pedagogical purposes.

Yet, a controversy involves not only experts, but also a host of social actors: typically public authorities, NGOs, local residents, or impacted users. The controversy inquiry discussed by Sadler et al. (2007) fosters the consideration of citizens' goals, but in an abstract way, as they are brought by teachers and pupils. We go further as we postulate that the social actors have something to teach us, that is, their unique point of view that is embedded in their singular experience and familiarity to the problem and its consequences. As far as socio-technical or environmental controversies are concerned, the various point of view of all concerned parties matter to enrich the problem and open new possibilities (Callon, Lascoumes and Barthe 2011). In this perspective they should become part of the learning process.

We thus opted to include this host of actors and their various points of view in a seminar course called "Integrated approaches to an environmental issue". This course has been part of the College of Science'si Master in Environmental Science and Management for about fifteen years. Since a different subject is taken up each yearii, the actors change annually. But each time, their testimonies illustrate the tension between making the problem intelligible and the need for a solution and closure (Smith et al. 2002). Indeed, the parties concerned with the controversy are the best teachers since tension, uncertainty, and caution are very much a part of their occupations. Our job, as "supervisors", is to ensure that the encounters are as fruitful as possible, to avoid turning the case into something cold and clinical (Fabre 2007, Hervé, Venturini and Albe 2013, Jimenez-Aleixandre, Rodriguez and Duschl 2000).

This article gives us the opportunity to describe how, in order to achieve our goals, students, the teaching staff, and the protagonists of a problematic situation may constitute a system we call a "triad". Building on the example of a case study, i.e. the case of flooding in Tubize (see Inset 1 below), we will focus on the main elements of our pedagogical set-up, its rules and its outputs. Then, we will share reflections about the learning process. To conclude, we will define this learning experience, its conditions of felicity and consequences, as an approach that we call "Public-based Learning". We will see that this learning approach is in line with the current stakes of environmental management and environmental manager's profession.

\section{THE TRIGGERING CASE}

\section{Flooding at Tubize challenges the place of water in modern cities.}

In contemporary environmental concerns, the "real world" is brimming over with problematic situations likely to offer a wealth of learning opportunities. This is especially true when they get broad media coverage that catches students' attention and induces their interest. That happened in 2011, when the Senne River and the canal near the small town of Tubize both burst their banks. This episode of flooding in Tubize, located some $25 \mathrm{~km}$ (14 miles) south of Brussels, made headlines in the Belgian press for weeks. Press articles introduced the various concerned parties - 
that is, the heterogeneous actors that expressed their views and brought up the issues in public. The main characteristics of the controversy were patent: the flood victims were no longer able to insure their property and faced the possibility of ruin, whereas the strong pressure of urbanization conducted more and more people to build their housing in the river's flood plain. Moreover, this especially affected a lowincome working-class population. Flood management was highly ineffective due to a lack of coordination between the concerned parties and due to the numerous connections between the Senne and the canal that made their behaviour unpredictable. The management was also thwarted by institutional and technical arrangements to protect the Brussels-Capital Region and its metro system from flooding, which were considered to have priority. Finally, much scientific uncertainty persisted as to the river's hydrology and ecology and the real effects of the flood control measures already taken.

Flooding in the Tubize area is a longstanding and very messy problem with a myriad of facets which involve strong, often tense, relationships: technical, economic, social, and even political. Like most environmental problems, the situation in Tubize is also characterised by various parties, with differing points of view, involved in a public controversy. None of them could assert "the one good way" to define the problem. Rather, the situation elicited a multitude of interpretations coming together dynamically, thereby giving rise to and fuelling controversy.

Insert 1. Repeated floodings at Tubize is one among many cases dealt by students and supervisors. It is a good example of what makes complex environmental situations tricky to manage: multiplicity of concerned parties, heterogeneous points of views, dynamic natural and social system, scientific uncertainties...

\section{THE PEDAGOGICAL SET-UP}

The public nature of a controversy has increased value for learning when it can be grasped through testimonies of the people affected by its management or its effects.

\section{The triad of actors}

According to Larochelle and Désautels (2007), the interactions between the actors are a keystone of any learning process. Most teaching approaches induce a format that reduces the teacher/pupil relationship to a transmission of stabilised knowledge to more or less passive individuals, even when they claim to be constructivist. This is especially the case in institutionalized scientific and technical curricula (Hervé, Venturini and Albe 2013, Jimenez-Aleixandre, Rodriguez and Duschl 2000, Savin-Baden 2000). We tried to avoid this trap right from the beginning.

From a constructivist perspective - as Larochelle and Désautels (2007) point out along with other colleagues (Sadler, Barab and Scott 2007, Salomon and Perkins 1998) - the relationships between teachers and students are radically different: teachers and learners cooperate in the learning process and they are altogether transformed by it. This is even more true in collaborative pedagogical set-ups. The learners learn from each other. The supervisors assume a new role: far from the transmission model, they guide active learners in building knowledge. This guiding 
role involves new teacher/pupil relationships which are part of a constructivist teaching model. Yet those relationships aren't tackled by the greater part of research in higher education (Larochelle and Désautels 2007, Salomon and Perkins 1998, Voß 2007). And we introduce a third figure to this learning situation, the various parties involved in the public controversies.

Two main issues must be addressed when learning from public controversies: How does the introduction of this third figure change the relationships between participants in the learning situation? How can we prevent those participants from adopting an academic format that simplifies, even rationalises, the case? Those issues can be analysed on several levels and we do not have the space to do that here. We will focus on the two main ones. The first level is the design of the pedagogical set-up that we've collectively developed by trial and error during our fifteen years of practice.

\section{The design of the pedagogical set-up}

The controversy case was explored by alternating several seminar activities, some of which belonged to the education frameworks specific to problem-based and situated learning: a real problem whose complexity is progressively revealed by a sequence of testimonies, collaborative team work sessions, tutoring, peer-to-peer feedback, intermediary personal output that allows regular supervisors' feed-back, and so on (Anderson, Reder and Simon 1996, Béchard 2001, Jonassen 1997, Lemaître 2007, Pedretti 1999, Savin-Baden 2000, Tan 2007). These activities were spread over two one-week periods ${ }^{\text {iii }}$ and took place in a precise chronology that is outlined in Figure 1.

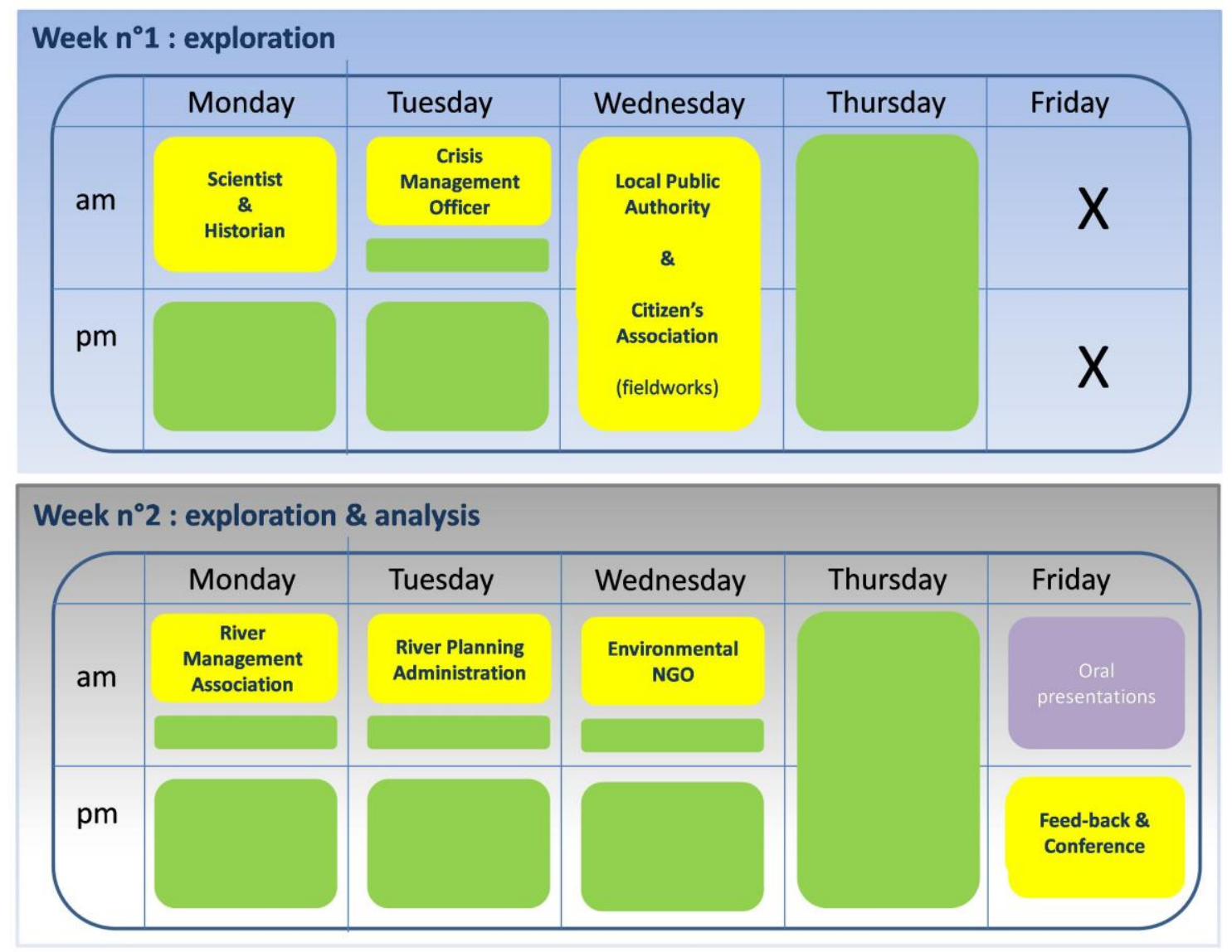

Figure 1. Program and timetable of the flood-management case study 
The key activity is encountering the various parties concerned by the controversy. On Monday, Tuesday, and Wednesday mornings we invite concerned parties one by one to meet the students in an auditorium, and to answer questions. Their introduction into the university classroom is carefully set-up. Choosing an appropriate panel of speakers is crucial: we are looking for a range of divergent and contrasting testimonies that open up multiple ways of defining the problem and we are aware that it is not possible to include every possible point of view. They are selected according to their legitimacy and their ability to engage in a specific communication format.

Indeed we carefully brief the speakers about our expectations: we ask them not to give explanations or to provide information. Instead we ask them to tell their story, share their experience and their views on the problem, and detail their practices and their doubts. This testimony format leads students and supervisors to make sense of the case rather than to analyze it. In other words they avoid reducing it to a narrow list of components. This is a key component of a successful exploration of the controversy.

When it comes to environmental problems, confirmation of spatial and concrete clues is helpful. So, in the middle of the first week, a field trip is organised. Besides visiting the very places where the problem occurs, the students also meet the actors concerned - typically residents and members of the local administration - and sometimes are guided by them in the field. Through this second activity the students can grasp the protagonists' experience, viewpoints, abilities, and expertise "in situ" (Masciotra 2007). For instance, seeing specific flooded locations helped them to appreciate the extent of the damage in Tubize and to make sense of the victims' dramatic experience.

Working in small groups is one of the cornerstones of all case study-based teaching methods to the extent that well-argued discussions of a problem help students both to make their conceptual networks complex and to generate new ones (Larochelle and Désautels 2007, Lewis and Leach 2006, Voß 2007). This collaborative team work takes place in the afternoons and on Thursdays. The group work gradually gets more demanding. During the first week, the students go through the testimonies using a theoretical and methodological framework (i.e. the CATWOE grid presented below) that they learn to use in the course of the process. As we shall see, this framework enables them to summarise and classify the various parties' viewpoints. During the second week, the students build on this framing process to compare the concerned parties' viewpoints and to identify the key stakes, that is, the ones that unveil tensions. They have to choose one of these stakes, to go deeply into the various points of view expressed about it, and finally to synthesize their findings for both students and supervisors in an oral presentation. A closing lecture given by a researcher or professional working on a similar situation helps students to build conclusions beyond the specific case.

In our group work approach, supervisors' role and position are radically different from the usual ones. Supervisors actually carry out the exercise along with the students. They discover the testimonies (and the facts) at the same time as the students. Consequently, they are no longer "the ones who know", and can no longer place themselves in the "authoritative communication" register (Hervé, Venturini and Albe 2013, Jimenez-Aleixandre, Rodriguez and Duschl 2000).

\section{The analytical equipment: The C.A.T.W.O.E Grid}

Another important aspect of our pedagogical set-up is the theoretical and methodological framework we use to help students summarise and classify the various parties' viewpoints. Actually, CATWOE is both the name of the analytical framework and a mnemonic device to remember what one must investigate in order 
to understand a problem and envision its solutioniv. The CATWOE is a management tool adapted to "messy situations": it deals with understanding problem contingencies, and making sense of a situation without reducing its complexity (Checkland 1985). It is summed up in Table 1.

Table 1. The CATWOE grid is designed as a simple checklist of items aiming to open reflection and to lean interpretation (Checkland $1998+1998$ ). While some of them $(\mathrm{E}, \mathrm{W}, \mathrm{O})$ specifically refer more to ways by which the actor defines the problem, others ( $T, A)$ refer to management strategies and their consequences for concerned the parties $(\mathrm{C})$.

\begin{tabular}{lll}
\hline C & "Customers" & $\begin{array}{l}\text { The victims or beneficiaries of } \\
\text { "T" }\end{array}$ \\
A & "Actors" & Those who would do "T" \\
"Transformation process" & $\begin{array}{l}\text { The conversion of input to } \\
\text { output }\end{array}$ \\
O & "Weltanschauung" & $\begin{array}{l}\text { The worldview which makes } \\
\text { this T meaningful in context }\end{array}$ \\
E & "Owner" & $\begin{array}{l}\text { Those who could stop "T" } \\
\text { "Environmental constraints" }\end{array}$ \\
& $\begin{array}{l}\text { Elements outside the system } \\
\text { which it takes as given }\end{array}$ \\
\hline
\end{tabular}

The CATWOE grid is a main element of our overall educational approach. Firstly, because it creates a common place between the concerned parties' testimonies and experiences, without leading the analysis to a false consensus. On the contrary, its categories highlight points of convergence and divergence between the various points of view (Weltanschauungen) and facilitate the identification and comparison of the key issues.

Beside respecting viewpoints' heterogeneity, it prevents supervisors and students from changing, sometimes unconsciously, their analytical criteria according to the speakers' presumed legitimacy, typically in a way that disqualifies statements from "ordinary people." With the help of the grid and with supervisors' feed-back, social hierarchies that students have integrated and that they reproduce are deconstructed. In this way, the CATWOE grid allows the concerned parties to be treated symmetrically without assigning them pre-established roles, interests, stakes, or identities.

Finally, by opening the category "actor" to natural and artificial objects - for example a river or a waterwork in the case of flooding in Tubize - supervisors and students are able to characterize the way those things actively "make a difference" in the situation, how they transform the problem and how they weigh on attempts to define it. This leads the collective to challenge the partition between nature and society on which most environmental management approaches are based. For instance, the case study of the floods in Tubize raised the question of the relationship with the river. The river appeared to be far more than a resource or a system to be managed: it is also a companion of man and a living entity seemingly driven by its own will, one that both resists and enchants us. Talking about "coexisting" with this entity, or "attachment" to it, would be more relevant for all the member of the triad. This proposition differs from the relationship of dominance that subtends the engineer's work, as well as from the banishment of objects from 
human society that social scientists utilize. Indeed, the stake of management practices shifts from identifying the technical solution to thinking about how we can live with the river.

To conclude, the combination of the triad, the set up and the CATWOE grid favour emergence, that is, they give rise to something unprecedented, which is not totally predictable and often surprising, but nevertheless positioned within a frame. As a result, students feel the need to address and complexify the problem and simultaneously to recognize that an urgent solution is required. In other words, they experience the tension between the two dimensions of managing any environmental problem, i.e., complexification and solving of the problem.

\section{The analytical outputs}

As in any case-based learning, we have to deal with the question: what is learned beyond the case? Indeed, each specific case studied is assumed to be representative of many complex environmental situations and the ways that they are generally managed. This representation is constantly challenged by supervisors in the course of group dynamics. It's also an issue that students explicitly have to tackle while exploring in depth the stake they intend to expose in their final group presentation. This final exercise doesn't only present students' evaluation. It is also a way to take the analysis to a more general level.

The generalisation process is twofold. On the one hand it is grounded in the analysis and comparison of the concerned parties' viewpoints. The conceptualisation work expected from students should maintain an explicit link with the situation being explored. It is also reinforced by the closing lecture given by a researcher or professional. This researcher or professional, who attends the students' oral presentations, is mandated to put the students' findings in perspective against the backdrop of his own work. He thus gives the students keys to go beyond the singularity of the situation studied and to give meaning to the approach in connection with their future professional practice.

What can be generalized depends on the chosen case and on the learning process. It is potentially different each time. In Inset 2 , we deliver the main analytical ouputs of the case study about flooding in Tubize. In that case study, students' generalization effort led them to identify and describe two contrasting nature management strategies.

\section{Two different experts' point of views on how to manage flooding at Tubize}

\section{According to the Civil servant in the Walloon Region's Directorate of Non-} navigable Waterways:

\section{Transformation}

Going from the current management scheme aimed at allowing the water "to flow as quickly as possible" to a management scheme that also allows one to "retain the water where it is possible".

\section{Customers}

To benefit people, their property, and their activities

\section{Actors}

First and foremost the Walloon Region's water resource managers, the owners of the land on which flood control works must be built, and the researchers and experts who advise the managers

Owner 
The Walloon Region and its managers, who have the powers, means, and know-how.

\section{Worldview}

Managed nature that is managed better and better through endless refinement of the procedures and techniques applicable to its various components (including human beings and their activities).

\section{Environment}

The Walloon Region's budget allows for financing only three "extraordinary projects a year".

"In the Walloon Region, only $2 \%$ of watercourses can still be considered natural" and " $10 \%$ of the land that is within $2 \mathrm{~m}$ of the banks [of the region's watercourses] is engineered in one way or the other".

\section{According to the civil servant in the Walloon Region's Crisis Unit:}

\section{Transformation}

"To get another more cross-cutting and interdisciplinary approach" to flood control adopted

\section{Customers}

To benefit the people, but also the river itself and its ecosystems

\section{Actors}

First and foremost the Transverse Group on Flooding (Groupe Transverse Inondations - (GRI)), which brings together not just the institutional managers of Wallonia's watercourses, but also the institutions responsible for spatial planning, academics, and stakeholders such as the River Contracts and environmental defence associations.

\section{Owner}

Those whose interests are challenged by this mapping and the water management plan PLUIE ("rain") and who are capable of initiating and winning a legal battle.

\section{Worldview}

"The river is a living entity. It has to be respected, without forgetting that, from time to time, it resumes its path..."

\section{Environment}

Climate change is exacerbating natural phenomena such as floods.

Insert 2. In the case of the Tubize floods, the students' conceptualisation work revealed two contrasting nature management strategies. These strategies are illustrated very clearly by comparing two experts in flood management's contradictory points of view as summarised with the CATWOE grid. Broadly speaking, we can see that using the CATWOE grid helps students to follow the actors as they themselves assign roles and identities, stakes and interests, i.e. as they perform operations that frame the problem.

\section{THE LEARNING PROCESS}

We previously mentioned that the entry of the parties into the learning process is carefully organised in order to create a defined relationship that we refer to as the 
triad. Positioning the triad (students, supervisors, concerned parties) at the core of our learning process encourages three distinctive aims: a modification of posture, that is perceptions of one's place in regard to the problematic situation, keeping symmetrical relations between actors in the learning process throughout the analysis and managing imbalances and emotional insecurity produced by the learning process.

\section{Changing postures}

Table 2. The different challenges faced by students, supervisors and publics lead them to a posture required both to explore the controversial case and to address environmental issues in their future professional practices.

\begin{tabular}{|c|c|c|c|}
\hline & Supervisors & Students & Speakers/Stakeholders \\
\hline Leaving aside & $\begin{array}{l}\text { Treating/rationalising the } \\
\text { problem; smoothing the } \\
\text { tensions and moments of } \\
\text { hesitation; }\end{array}$ & $\begin{array}{l}\text { Presenting themselves as (future) } \\
\text { specialists; hierarchizing the } \\
\text { points of view; trying to find out } \\
\text { who is right and who is wrong; } \\
\text { searching for consensus }\end{array}$ & Being spokespeople only \\
\hline \multirow[t]{2}{*}{ Excerpts } & $\begin{array}{l}\text { "It is time to wrap up, } \\
\text { because it is becoming too } \\
\text { complex..." }\end{array}$ & $\begin{array}{l}\text { "But to what degree do you have } \\
\text { to be able to talk about scientific } \\
\text { and technical matters?" (question } \\
\text { put to a residents' association) }\end{array}$ & $\begin{array}{l}\text { "That's precisely it. I claim } \\
\text { the right to express my } \\
\text { views on these matters as a } \\
\text { citizen." (a scientist) }\end{array}$ \\
\hline & $\begin{array}{l}\text { "If things are not put in their } \\
\text { place on the scientific level, } \\
\text { what good are these } \\
\text { exercises?" }\end{array}$ & & $\begin{array}{l}\text { "I am the association's } \\
\text { president, but I am also a } \\
\text { woman and mother. How } \\
\text { can I guarantee my } \\
\text { children's welfare?" }\end{array}$ \\
\hline \multirow[t]{3}{*}{$\begin{array}{l}\text { Bringing } \\
\text { about }\end{array}$} & $\begin{array}{l}\text { Tension and connections } \\
\text { between } \\
\text { keeping and problem } \\
\text { solving }\end{array}$ & \multirow[t]{3}{*}{$\begin{array}{l}\text { Stepping back } \\
\text { Investment in terms of oneself and } \\
\text { work; accepting different types of } \\
\text { expertise }\end{array}$} & \multirow{3}{*}{$\begin{array}{l}\text { How they do their work, } \\
\text { including hesitation and } \\
\text { tension } \\
\text { Communication format of } \\
\text { the testimony }\end{array}$} \\
\hline & $\begin{array}{l}\text { Giving life to and letting the } \\
\text { dimensions co-exist }\end{array}$ & & \\
\hline & $\begin{array}{l}\text { Adopting a position of } \\
\text { retreat to let other forms of } \\
\text { expertise take their place }\end{array}$ & & \\
\hline
\end{tabular}

Each type of actor involved in the learning process is led to adopt an attitude that contrasts with the institutionalised formations and social hierarchy of expertise. Entering into a collective learning process requires each of the three groups to leave aside something and take up other things. They must all give up any framework that leads to a hierarchy between viewpoints. They also must separate knowledge issues 
from political and practical ones, and erase tensions and doubts. This shift from cognitive routines can only be achieved by a serious reflexivity effort. But this brings on the numerous and manifold trials that are very much the essence of environmental management. The combination of these two shifts results in the posture that is outlined in table 2 .

The change of posture is important for several reasons. As we pointed out, by inducing a cognitive and emotional imbalance, it enables each player to challenge the representations and routines that enable them, by applying a ready-made frame to a new situation, too easily to avoid exploring the situation (Kittleson and Southerland 2004, Voß 2007).

Next, it draws attention to what is made invisible by the "rational myth" (Hatchuel 2000) beyond the teaching model of transmission of stabilised knowledge. The students discover environmental management in practice and its avatars: the tension between its two constituent movements, i.e., complexification/opening up of the problem and resolution/closure of the problem, the intricate issues on different scales of time, space, and relations, i.e., their indeterminateness and the emotions that are brought about both by the concerned parties and the students' reception of testimonies of dramatic experiences.

In other words, environmental management is far from a "decide-andimplement" diptych. It's a practice that scaffolds the dimensions of the problem as well as the actors' positions and the limits of what they know or are able to learn. As professionals, they will have to negotiate solutions with both experts and laypeople, and more specifically, to do it in situ. From this perspective, the questioning and objections of these actors can no longer be considered as demonstrations of incompetence. Instead, they inspire innovations: objecting doesn't mean opposing, it's extending, it's opening up deliberation about possible worlds.

\section{Keeping symmetry}

Secondly, the relationships amongst the actors involved in the learning process are made as symmetrical as possible. As each actor in the triad is shifted and therefore experiences discomfort, symmetry is produced that enables them to meet each other in their respective positions. The supervisors, students, and, to a certain extent, the concerned parties are brought to realise that they have one amongst other possible points of view, depending on their knowledge, world view, and position in a social framework, amongst other things. In the course of the group discussions the students gradually acquire the ability to state explicitly and to discuss this point of view, provided that exploring the divergences is allowed and utilized in the learning set-up (Daniels and Walker 1996, Pedretti 1999).

This symmetry also extends to the relationship between the supervisors and students regarding the collaborative learning process. As we mentioned before, supervisors discovered details at the same time as students - whilst they gather a minimum amount of information in order to select a case study. All members of the triad have to cope with the uncertainties of the controversy itself and with issues that they can't grasp due to their background, even the supervisors, as they come from a diversity of fields and research teams. This places everyone in a symmetrical stance with regards to the complexity of environmental situations.

On the other hand, the supervisors built up appropriate skills by exploring former cases studies on different topics: how to use the theoretical and methodological framework in order to get the issues to come to light and to define the points of view involved. In this learning process, supervisors' guiding role means sharing those experiences with the students, introducing them to an unfamiliar educational set-up, and providing support and guidance for methodological 
pathways. This facilitation work reduces the asymmetrical distribution of resources throughout the exercise.

This shared experience results in symmetryv between supervisors as well. They share a way of learning and of realising a controversy inquiry. This process challenges their disciplinary assumptions and their specific practices. It shakes up the legitimacy and hierarchy of different kinds of knowledge, and puts them at risk as the supervisor's and student's respective positions became blurred (Melville \& Pilot, 2014). This supporting role, the sharing of experiences, the doubts and the risk that each supervisor faces in their own way are also part of our approach.

Finally, as we already pointed out, parties' points of view are explored symmetrically. No privilege is granted to scientific discourse. This approach isn't spontaneous for the students, who had already assumed the culture of over-esteem for objective, rational, and scientific knowledge during their university education. As the supervisors team repeatedly observed, following Pouliot (2008), this culture leads them to opt in the first instance for a [role-] delegation model for managing controversy (Callon, Lascoumes and Barthe 2011). Students spontaneously give to scientists the role of producing legitimate scientific knowledge and of informing ordinary people in reference to this model. In the same way, they give politicians and institutions the role of representing the general interest and of guiding populations' behaviour. And finally they gave the people, i.e., "ordinary" people, the role of receiving information and guidance from the scientists and politicians and of endorsing the constraints of the solutions imposed to them by the latter. This role is at best due to a lack of information and at worst due to an irrational or uncivil attitude. Requirements for symmetrical treatment challenge the "delegation model" to open up new possibilities in the area of environmental management.

Our approach's need for symmetry plays a central role in our pedagogy Along with the CATWOE grid, the supervisors' facilitation work has a central role to play, because it underlines the more or less conscious postulates and hierarchies beyond the students' contribution to the discussions. The regular feedback given to students stresses the refusal to dispel divergences between them. Supervisors foster the need to give up the idea that they expect a single right answer. This respect for the indeterminateness and diversity is also what prevents the case from "cooling down" in the constructivist learning process (Hervé, Venturini and Albe 2013, Larochelle and Désautels 2007, Voß 2007).

\section{Generating and coping with insecurity}

To generate productive relationships amongst triad members, we demand costly changes from them. These more or less imposed changes can give birth to a feeling of insecurity.

Several authors have stressed the discomfort of teachers (Dahlgren, Castensson and Dahlgren 1998, Voß 2007) and learners (Albe 2008b, Kittleson and Southerland 2004) involved in this type of education. The supervisors can no longer draw on asymmetrical resources or on a ready-made solution to reduce the risk of failing and revealing to students their incompetences. They could lose a legitimacy that is central to their professional identity.

We extended this discomfort to the concerned parties who agreed to share their practices and experiences and unveil their fragility. Indeed, articulating practices always involves some tinkering, doubts, and risky connections that the actors usually strive to keep in the wings in order to not expose themselves.

Focusing on doubts, tensions and sometimes failures is an unprecedented learning experience for students, light-years away from the academic settings in which they have been socialised. We demand a lot of them: to welcome complexity and tensions, as well as confrontation and resistance, to integrate the discovery that 
uncertainty "is part of the job", to give up the familiar rational myth, to change their positions/attitudes and to establish new relationships with their supervisors... All these changes, experienced at the same time, create a cognitive and emotional imbalance that leads some of them to hesitate and often to resist the process - at least at the beginning!

Our educational approach includes specific ways of managing imbalances and insecurities in order to allow the triad to come to life and achieve the best results from the learning process. The main principles of the process - symmetric treatment, no privilege allowed to scientific knowledge, a focus on exploration rather than solution - are carefully explained to the concerned parties. Their reaction to these explanations - or promises - is most often surprise and interest. A kind of confidentiality is also guaranteed as information obtained is never disclosed outside the classroom and is never reused for other purposes.

The scheme's organisation, that is, two-week long sessions devoted entirely to studying the case, also aims to create confidence. This organisation breaks the academic rhythm and puts on hold other concerns including academic issues, research projects, and even daily life routines like checking e-mail. Students and supervisors are allowed to take the time needed to explore and to debate, they get somehow "haunted" by the subject. The sequence of the activities and of concerned parties' testimonies is carefully scheduled in order for the students to face gradual challenges, progressively deepen their insight of the case, improve their methodological skills and enter into a new posture gradually.

The CATWOE grid is also a source of reassurance for both supervisors and students. The learning process requires them to deal with "the intriguing facts", i.e. facts that reveal the tensions at work, that come out of the testimonies. The CATWOE grid makes it possible to manage this surprise by prompting both the sorting of the wealth of information and the interpretation of these intriguing facts.

\section{CONCLUSIONS: Defining Public-based Learning}

Even if our pedagogical approach borrows from Problem-based learning, the inclusion of concerned parties and the specific mode of inclusion make it radically different. The people we refer to as " concerned parties" are concerned both because they are affected by the consequences of other groups' goals or actions and because they are committed to getting these consequences acknowledged as stakes and questions challenging our societies' choice and future that is, as public issues. In this respect, they commit themselves to a kind of social inquiry. They match the Dewey (1927) concept of "public".

We can define our approach as "Public-based-learning" building around four ideas associated with public.

Firstly, the case study should be tackled through the consequences of a situation or action. So the publics emerging from a controversy and their viewpoints should be identified. Moreover they should be considered as resources for understanding the world. That is to say, they are best placed to express their point of view, to testify on consequences and the ways they relate the problem to other actors - human or non human ones -, to reveal tensions and blind points in knowledge fields and management strategies. They thus may become a partner in a pragmatic learning process.

Secondly, some conditions of felicity have to be fulfilled to make their contribution fruitful. The main ones rely on the triad configuration we developed throughout this paper. The concerned parties invited as speakers are selected according to their ability to adopt a communication format of testimony that unveils practices, hesitations and tensions. The pedagogical set-up must also favor symmetrical relationships between actors of the learning process as the diversity of 
positions and expertise are welcomed, as well as between the points of view that are actually analyzed throughout the exercise. The CATWOE grid is convenient to ensure students and supervisors will use the same analytical criteria for all of them. It is also helpful to manage imbalances and insecurities and make them contributive to the learning process.

The keystone of the triad and the learning process is the shift to a posture that leaves aside conventional roles and hierarchies, to avoid a priori identities and stakes of people and objects and to give up the rational myth that separates knowledge issues from political and practical ones. The point is to become open to discovering how concerned parties define and connect those elements in situ and through the controversy dynamic - or at least through its translation and reinvention as allowed by the pedagogical set-up.

This leads to the third dimension we would like to stress. Public-based-learning opens the door to other relationships with publics both in educational and professional contexts. The publics are neither the subject of research according to the social science model, nor are they mute and disciplined recipients of environmental measures and techniques that are expected by most technical and political frameworks. Instead, the publics involved in an issue are the entity by which ambiguity is brought up. The latter is understood as the connection of rational knowledge and less precise, less explicit, but nonetheless crucial dimensions of the human being's reality (Wynne 2002). In this respect, ambiguity becomes a resource for investigating, (re)framing the problem, and exploring possible worlds. The process on which we embarked with the actors is one of collective learning in which their legitimacy as publics concerned by the problem at hand (in the case of the flood victims and their association) was recognised and their knowledge, practices, and experiences were valued.

Consequently, the fourth characteristic of Public-based-Learning is an epistemic one. The triad, and especially the requirements for symmetry and posture, put the problem or problems (that is no longer the framework for the learning situation) aside. Instead, the extent to which this problem or problems are put forward, even transfigured, by these publics comes first. The intersubjective meetings with the concerned parties and the mutual enrichment contribute to a learning process that is singular, situated, not totally predictable and often surprising. This learning approach enables students to acquire knowledge specific to the environmental problem studied. Yet mainly they learn a heuristic, if not a methodology, that enables an integrated approach of environmental controversies and, along the with the constructivist pedagogy tools (like collaborative team group, debates, supervisors' facilitator role, etc.) develops students' critical mind, which is central both to a university course and to a professional performance.

Indeed the conceptual purposes of this heuristic are to preserve the complexity of the case studied - and the environmental issues in general -, to uncover the tensions and uncertainties embedded in the attempts to frame and manage the controversy, and to explore how the concerned parties connect the elements of the problem. It is conducive to hybridisation of the possible world comprehensions (Larochelle and Désautels 2007), which is an essential part of any negotiation process.

In addition, the practical purposes of this heuristic are to initiate students to a dialogue-based model for managing the environmental problems that they will face in their working lives (Karl, Susskind, \& Wallace, 2007). Since all parties concerned with a public controversy make exploitable contributions, they can and must fruitfully take part in the discussion todefine the problem, and to collaborate both on a legitimate generation of knowledge and on building and evaluating possible ways to manage the situation (Callon, Lascoumes and Barthe 2011). This heuristic enables them above all to learn how the tension between the complexification and solving of the problem can be managed in situ and with the publics. 
These are added values of Public-based-learning. They are directly linked to the type of professional profile associated with the Masters in Environmental Science and Management. These future environmental managers will be "practitioners" first and foremost. A practitioner is not a second-class professional who knows a little of everything but nothing in depth. On the contrary, practitioners are on the front lines; they have to tackle the multiple dimensions, ambiguities, and the uncertainty of real-life situations. They must explore and integrate these parameters when elaborating a diagnosis and the possible strategies for solving the problem(s), and characterizing each strategy's consequences. While they cannot claim to see the whole picture and are forced to dialog with the various publics, their added value is their ability to become mediators, who connect publics and issues, practices and knowledge, and the need for enriching the problem to the need for solving it (DuPuis and Ball 2013, Sauvé 1999).

This definition is in line with the current stakes of environmental management and environmental manager's profession rather than those of discipline or curricula requirements. This practice should be recognised for its own value and would be placed at the core of environmental managers' professional identity. As far as this practice is concerned, training environmental professionals calls for developing other skills, aptitudes, and attitudes, namely: a non-essentialist exploratory attitude, savviness and reflexivity, a conscious renunciation of disqualifying and ranking points of view, and the ability to capitalise on situated experiences and to deal with uncertainty and insecurity. Mostly it requires helping future environmental managers to find the courage to give deliberation its rightful place and to allow confrontation and collective learning, in order to engage in a non-violent communication mode and to negotiate the limits of one's interaction with the concerned parties.

All these cannot entirely be taught in the traditional sense of the word nor fostered by the traditional teaching model of transmitting information and applying knowledge. As far as learning is concerned, the pathway is the one of experience construed in the etymological sense of experiri ("to try"), that is, as a trial (Trepos 1996) in which the relationships, identities, and abilities of the human and nonhuman actors involved in a situation are played over and over and redeployed. That is what the Public-based Learning approach tries to achieve.

\section{REFERENCES}

Albe, Virginie. 2008. "Students' Positions and Considerations of Scientific Evidence about a Controversial Socioscientific Issue." Science \& Education 17(8-9):805-27.

Anderson, John R, Lynne M Reder and Herbert A Simon. 1996. "Situated Learning and Education." Educational researcher 25(4):5-11.

Béchard, Jean-Pierre. 2001. "L'enseignement supérieur et les innovations pédagogiques: Une recension des écrits." Revue des sciences de l'éducation 27(2):257-81.

Callon, Michel, Pierre Lascoumes and Yannick Barthe. 2011. Acting in an Uncertain World: An Essay on Technical Democracy. Boston: The MIT Press.

Checkland, Peter. 1985. "From Optimizing to Learning: A Development of Systems Thinking for the 1990s." The Journal of the Operational Research Society 36(9):757-67. doi: $10.2307 / 2582164$.

Dahlgren, Madeleine Abrandt, Reinhold Castensson and Lars Owe Dahlgren. 1998. "PBL from the Teachers' Perspective." Higher Education 36(4):437-47.

Daniels, Steven E. and Gregg B. Walker. 1996. "Collaborative Learning: Improving Public Deliberation in Ecosystem-Based Management." Environmental Impact Assessment Review 16(2):71-102. doi: http://dx.doi.org/10.1016/0195-9255(96)00003-0.

Dewey, Johh, 1927. The Public and its Problems: An Essay in Political Inquiry. In The Later Works of John Dewey, 1925-1953, Jo Ann Boysdston (Ed.), Vol. 2, 1925-1927, pp. 235372 (Carbondale, Southern Illinois University Press, 1988). 
DuPuis, E Melanie and Tamara Ball. 2013. "How Not What: Teaching Sustainability as Process." Sustainability: Science, Practice, \& Policy 9(1):64-75.

Fabre, Michel. 2007. "Des savoirs scolaires sans problèmes et sans enjeux. La faute à qui?". Revue française de pédagogie:69-78.

Hatchuel, Armand. 2000. "Quel horizon pour les sciences de gestion? Vers une théorie de l'action collective." pp. 7-43 in Les Nouvelles Fondations Des Sciences De Gestion. Eléments D'épistémologie De La Recherche En Management, Fnege. Paris: Vuibert.

Hervé, Nicolas, Patrice Venturini and Virginie Albe. 2013. "Enseigner un savoir stabilisé et une controverse socioscientifique, quelles différences et similitudes? Exemple d'une pratique ordinaire d'enseignement en physique." Les dossiers des sciences de l'éducation (29):45-66.

Jimenez-Aleixandre, M Pilar, Anxela Bugallo Rodriguez and Richard A Duschl. 2000. "' Doing the Lesson' or 'Doing Science': Argument in High School Genetics." Science Education 84(6):757-92.

Jonassen, David H. 1997. "Instructional Design Models for Well-Structured and Ill-Structured Problem-solving Learning Outcomes." Educational Technology Research and Development 45(1):65-94.

Karl, H. A., Susskind, L. E., \& Wallace, K. H. (2007). A Dialogue not a Diatribe. Effective Integration of Science and Policy through Joint Fact Finding. Environment, 49(1), 20-34.

Melville, W., \& Pilot, J. (2014). Storylines and the Acceptance of Uncertainty in Science Education. International Journal of Environmental \& Science Education, 9(4), 353-368.

Kittleson, Julie M and Sherry A Southerland. 2004. "The Role of Discourse in Group Knowledge Construction: A Case Study of Engineering Students." Journal of Research in Science Teaching 41(3):267-93.

Larochelle, Marie and Jacques Désautels. 2007. "On Ernst Von Glasersfeld's Contribution to Education: One Interpretation, One Example." Constructivist Foundations 2(2-3):90-97.

Lemaître, Denis. 2007. "Mobilisations De La Forme 'Problème' Dans Les Pédagogies De L'enseignement Supérieur." Pp. 12 in Congrès international AREF 2007, Actualité de la recherche en éducation et en formation. Strasbourg: Centre pour la Communication Scientifique Directe.

Lewis, Jenny and John Leach. 2006. "Discussion of Socio-scientific Issues: The Role of Science Knowledge." International Journal of Science Education 28(11):1267-87.

Masciotra, Domenico. 2007. "L'agir Compétent: Une approche situationnelle." Consulted on the internet the 3.02.2010: http://www.ore.uqam.ca/Documentation/Masciorta/Masciorta04.pdf.

Melville, Wayne and Jason Pilot. 2014. "Storylines and the Acceptance of Uncertainty in Science Education." International Journal of Environmental \& Science Education 9(4):353-68.

Pedretti, Erminia. 1999. "Decision Making and STS Education: Exploring Scientific Knowledge and Social Responsibility in Schools and Science Centers through an Issuesbased Approach." School Science and Mathematics 99(4):174-81.

Pouliot, Chantal. 2008. "Students' Inventory of Social Actors Concerned by the Controversy Surrounding Cellular Telephones: A Case Study." Science education 92(3):543-59.

Sadler, Troy D, Sasha A Barab and Brianna Scott. 2007. "What Do Students Gain by Engaging in Socioscientific Inquiry?". Research in Science Education 37(4):371-91.

Salomon, Gavriel and David N. Perkins. 1998. "Individual and Social Aspects of Learning." Review of Research in Education (23):1-24.

Sauvé, Lucie. 1999. "Environmental Education between Modernity and Postmodernity: Searching for an Integrating Educational Framework." Canadian Journal of Environmental Education (CJEE) 4(1):pp. 9-35.

Savery, John R. 2006. "Overview of Problem-based Learning: Definitions and Distinctions." Interdisciplinary Journal of Problem-based Learning 1(1):3.

Savin-Baden, Maggi. 2000. Problem-based Learning in Higher Education: Untold Stories: McGraw-Hill International.

Smith, Barbara Herrnstein, E Roy Weintraub, John Law and Annemarie Mol. 2002. Complexities: Social Studies of Knowledge Practices: Duke University Press. 
Tan, Oon-Seng. 2007. "Problem-based Learning Pedagogies: Psychological Processes and Enhancement of Intelligences." Educational Research for Policy and Practice 6(2):10114.

Trepos, Jean-Yves. 1996. La Sociologie de L'expertise., Vol. 3119. Paris: Presses Universitaires de France.

Voß, Reinhard. 2007. "To Find a Daisy in December: Impressions of Ernst Von Glasersfeld and an Interview with Him about Constructivism and Education." Constructivist Foundations 2(2-3):85-89.

Wynne, Brian. 2002. "Risk and Environment as Legitimatory Discourses of Technology: Reflexivity Inside Out?". Current Sociology 50(3):459-77.

\footnotetext{
'This Master in Environmental Science and Management is organized by the College of Science's of the University of Liège, Belgium. This program is opened to students graduated with bachelors in Sciences', Applied Sciences' and Human Sciences' disciplines.

ii The subject is chosen with the help of several criteria: it is related to one or several environmental stakes prompted at the forefront by a public controversy; it can be explored through a specific case at a local level; it must be manageable within 2 weeks; and it must be convenient for using the CATWOE grid. Beside the repeated flooding at Tubize, which is exposed in this article, we explored for examples wild fauna management stakes through the explosion and the spreading of beaver populations in southern Wallonia, the future of our energetic model through the case of Tihange nuclear plant in Belgium, or public health impacts of electromagnetic waves through the set up of a mobile phone antenna in a Belgian rural city.

iii The rationale of the separation is to give students time to integrate the learning outcomes of the first period.

iv Incidentally, we don't thoroughly follow the soft-system-analysis' pathway as we don't use CATWOE to select the right mode of resolution that must be endorsed by all protagonists. We use it to enable students to explore a specific problem, to try to characterize relationships, and existing or potential tensions. Our expected outputs are analytical ones.

${ }^{v}$ This augured nothing as to a consensus on or common definition of the problem: Here, too, respect for the diversity of viewpoints was upheld.
} 